\title{
Pearly penile papules
}

\section{Commentary}

\author{
J K Oates
}

Pearly penile papules (PPP) (also often referred to as pink pearly papules or pink penile papules) have been noted by many anatomists and dermatologists over the past 250 years, including such distinguished names as Littré and Morgagni. They commonly present to clinics for sexually transmitted diseases as one of the minor "rarities" and the source of much anxiety for worried adolescents.

No agreement has been reached on their incidence and their natural history is not clearly understood. As the Case report in this issue $^{1}$ shows, new facts about the shape, genital sites and age incidence of PPP are still being reported.

In one of the earliest studies Buschke ${ }^{2}$ noted their presence in 36 of 435 of men and boys examined. They were seen only in patients between the ages of 24 and 41 years. Buschke and Gumpert $^{3}$ in a later study found them in $20 \%$ of males. Neinstein and Goldenring found PPP to be present in $15.2 \%$ of 151 adolescents (mean age $17 \cdot 2$ years, range 11-22). No PPP were found under the age of 14 years. Eighty per cent of patients were circumcised but there was no statistically significant association between the presence of PPP and race, sexual activity or the circumcised state.

Glicksman and Freeman ${ }^{5}$ found the lesions present in $20 \%$ of 229 males with an age span of 16 to 78 years. They noted no PPP in patients over 41 years of age. Winer and Winer ${ }^{6}$ reviewing the literature up to 1995 found all recorded patients were under the age of 41 while Cordiviola et $a l^{7}$ after examining 2040 patients, were able to find only one with PPP. Neri et $a l^{1}$ claim that their patient appears to be the only pediatric case reported in the literature though, as the authors point out, Buschke ${ }^{2}$ stated that structures similar to PPP had been observed in the newborn and his illustration of apparently typical lesions present in a neonate is reproduced by Dickenson, ${ }^{8}$ in his Atlas of Human Sexual Anatomy.

The papules vary somewhat in shape, size, and colour though the lesions are all identical in an individual. PPP range from dome or conical shaped lesions, about 1 to $2 \mathrm{~mm}$ wide, and from 1 to $2 \mathrm{~mm}$ or rarely more in height. Small globular protuberances are common whilst angular forms are sometimes seen. The annular forms described by Neri et $a l^{1}$ have not been previously recorded.

Their colour may be pink, white, yellow or rarely almost transparent. They are commonly found in a single or double row on the corona which may partially or completely encircle the glans. They tend to be most prominent on the dorsum of the glans and to fade somewhat as they approach the fraenum. Unusually they may be found on the glans itself but are associated with typical coronal lesions. ${ }^{9}$

Only two cases appear to have been recorded of PPP on the shaft of the penis, one by O'Neil and Hansen ${ }^{10}$ while the boy reported by Neri et $a l^{1}$ is the only case without additional papules on the glans or corona.

The age at which PPP actually appear is not clear but they are certainly mostly noted in late puberty, adolescence and young manhood when sexual interest and activity are at a height. Although PPP may be present before puberty, ${ }^{12}$ this must be a rare occurrence. A prevalence of $10-20 \%$ in babies would be unlikely to go unreported by paediatricians and paediatric urologists. It is uncertain if the lesions persist in old age; I have seen them in men in their early fifties.

Histological reports are uniform in their findings showing a thinned epithelium overlying areas of fibrosis and vascular proliferation in the upper dermis. A mild lymphocytic infiltration is commonly present. Neri et $a l^{1}$ found no nerve fibres in any of the papules they biopsied. Tannenbaum and Becker, ${ }^{11}$ however, identified groups of non myelinated fibres in the upper layer of the tunica propria. These fibres formed ovoid structures into which one or more myelinated fibres were seen to enter. Similar structures were noted in the papillary layer of biopsy specimens taken from the coronal region in patients who did not have papules. Both were considered to be normal mucocutaneous sensory end organs and their presence in PPP had no special significance.

Penile papules are found in many animals including cats, dogs and some chimpanzees. ${ }^{12}{ }^{13}$ Those seen in the cat for example are very prominent, resembling spines.

In man the possibility has been considered that PPP may stimulate the vagina during intercourse but in view of their very small size this seems to be extremely unlikely. Patients with PPP have never reported them as having any erogenous function. They appear to fulfil no specific purpose in men and the suggestion by Callomon and Wilson ${ }^{9}$ that they may represent phylogenetic residua from our animal ancestry is almost certainly correct.

No treatment other than reassurance is required and requests from patients for surgical removal for cosmetic reasons should generally be resisted.

1 Neri I, Bardazzi F, Raone B, Negosanti M, Patrizi A Ectopic pearly penile papules: a paediatric case.

2 Buschke A. Uber die Bedeutung der papillen der coronen glandis. Med Klin 1909;5:1621-5.

3 Buschke A, Gumpert H. Die papillen an der corona glandis; in Vergleichend-Aanatomischer und Ethnologischer Beziehung. Arch $f$ Frauenk 1925;11:43-6.

4 Neinstein LS, Goldenring J. Pink pearly papules: an epidemiological study. F Pediatr 1984;105:594-5.
76 Glengall Road, Essex IG8 0DL, UK J K Oates

Accepted for publication 4 October 1996 
5 Glicksman JM, Freeman RG. Pearly penile papules: a statistical study of incidence. Arch Dermatol 1966 93:56-2.

6 Winer JH, Winer LH. Hirsutoid papillomas of coronal margin of glans penis. $\mathcal{F}$ Urol 1955;74:375-7.

7 Cordiviola LA, Sanchez Caballero HJ, Bosq P. Hirsuties papillaris penis de Maiocchi. Sem Med Buenos Aires 1957; papillaris penis

8 Dickinson RL. Atlas of human sexual anatomy. Baltimore: Williams \& Wilkinson, 1949. 2nd ed (fig 118).
9 Callomon FT, Wilson JF. The nonvenereal diseases of the genitals. Springfield, IL: Charles C Thomas, 1956.

10 O'Neil CA, Hansen RC. Pearly penile papules on the shaft. Arch Dermatol 1995;131:491-2.

11 Tannenbaum MH, Becker SW. Papillae of the corona of the glans penis. $\mathcal{F}$ Urol 1965;93:391-2.

12 Bloom F. Pathology of the dog and cat. Evanston, IL: American Veterinary Publications, 1954:263.

13 Hill WC. Notes on the male external genitalia of the chim-ه panzee. Proc Zool Soc Lond 1946;116:129-31. 